\title{
Playing table tennis contributes to better agility performance in middle-aged and older subjects
}

\author{
Henrieta Horníková*, Ladislava Doležajová, and Erika Zemková \\ Faculty of Physical Education and Sport, Comenius University in Bratislava, Bratislava, Slovak Republic
}

Copyright: (c) 2018 H. Horníková et al. This is an open access article licensed under the Creative Commons Attribution License (http://creativecommons.org/licenses/by/4.0/).

Background: Both reaction time and agility times increase with advancing age. However, it is not whether and to what extent regular practise of sport such as table tennis contributes to faster decision-making and movement speed in middle-aged and older adults. Objective: The aim of this study was to compare agility time in table tennis players and sedentary subjects of different ages and also to investigate the relationship between agility time and age in these groups. Methods: Forty four young, early middle-aged, late middle-aged and older table tennis players and forty eight sedentary subjects of matched age performed the agility test consisting of movement reactions to visual stimuli. Results: ANCOVA revealed a significant difference in agility time between table tennis players and sedentary subjects when the effect of age was controlled $(F(1,89)=46.1, p<.001)$. Agility time was significantly shorter in early middle-aged ( $435.8 \pm 35.6 \mathrm{~ms}$ and $483.8 \pm 36.5 \mathrm{~ms}$, respectively; $p=.006)$, late middle-aged $(481.0 \pm 36.8 \mathrm{~ms}$ and $530.7 \pm 31.8 \mathrm{~ms}$, respectively; $p=.004)$ and older (500.9 $\pm 24.4 \mathrm{~ms}$ and $564.5 \pm 44.9 \mathrm{~ms}$, respectively; $p=.007$ ) table tennis players than sedentary subjects. In addition, there was a significant relationship between agility time and age in sedentary subjects $\left(r_{\mathrm{p}}=.73, p<.001\right)$ and table tennis players $\left(r_{\mathrm{p}}=.53, p<.001\right)$. Conclusions: Agility time is shorter in early middle-aged, late middle-aged and older ( $>60$ years) table tennis players compared to age-matched sedentary subjects $(9.9 \%, 9.4 \%$, and $11.3 \%$, respectively).

Keywords: aging, agility test, athletes, sedentary

\section{Introduction}

The normal aging process is associated with declines in certain cognitive functions, such as processing speed and certain memory, language, visuospatial, and executive function abilities (Harada, Natelson Love, \& Triebel, 2013). More components of cognitive function are related to complex reaction time. Thus, reaction time tests could serve as a reflection of cognitive function (Jakobsen, Sorensen, Rask, Jensen, \& Kondrup, 2011).

Simple reaction time decreases from infancy until age of 20-30 then shows little slowing down until around 50 years (Der \& Deary, 2006; Luchies et al., 2002). Also choice reaction time decreases throughout the adulthood (Der \& Deary, 2006). The study by Chandak and Makwana (2012) reported increase

\footnotetext{
* Address for correspondence: Henrieta Horníková, Faculty of Physical Education and Sport, Comenius University in Bratislava, Nábrežie armádneho generála Ludvíka Svobodu 42e98/9, 81469 Bratislava, Slovak Republic. E-mail: hornikova.henrieta@gmail.com
}

of choice reaction time about $6.2 \%$ between age $21-45$ and 46-60 years. Recent research (Woods, Wyma, Yund, Herron, \& Reed, 2015) showed that choice reaction time latencies increased significantly with advancing age $\left(r_{\mathrm{p}}=.47,2.80 \mathrm{~ms} / \mathrm{year}\right)$ of which more than $80 \%$ of age-related choice reaction time slowing down accounted for central processing time (isolated by subtracting simple reaction time) due to slower motor responses.

This age-related choice reaction time can be improved by exercise, motor training and pharmaceutical agents (Seidler et al., 2010). In particular, participation in racquet sports (e.g., badminton or tennis) can reduce reaction time (Dube, Mungal, \& Kulkarni, 2014; Foroghipour, Monfared, Pirmohammadi, \& Saboonchi, 2013; Vidja, Bhabhor, Sarvaiya, Patel, \& Joshi, 2015).

One of the most suitable sports for improving reaction time is table tennis. Sports such as table tennis, badminton, tennis or squash have been classified as reaction sports (Yoshida et al., 1995). Furthermore, table tennis is one of the fastest sports (Ak \& Kocak, 2010) and long-term playing improves visual reaction 
time (Vidja et al., 2012). Therefore it is obvious that table tennis players have significantly shorter reaction time than non-table tennis players (Bhabhor et al., 2013) even also shorter than tennis players (Can, Kilit, Arslan, \& Suveren, 2014).

In these reaction sports both quick reaction and speed of movement response are considered to be the most important abilities of athlete's performance. It is known that an agility time consists of stimulus perception, decision-making and execution of movement (Zemková \& Hamar, 2015). Intensive practise of table tennis improves perceptual, decision-making and motor systems (Padulo et al., 2016). It may be corroborated that playing table tennis can improve choice reaction time as well as speed of motor response. For example, one semester course of playing table tennis improved agility time in non-athlete students (Vacenovský \& Vencúrik, 2013). Table tennis players displayed the fastest agility time compared to players of the other sports (Zemková \& Hamar, 2015).

Agility skills are well investigated in young athletes but in older subjects less. It seems that table tennis can contribute suitably to keep a good level of agility performance especially in older people. It was found that fast and appropriate step responses are an important predictor of falls risk in older people (Lord \& Fitzpatrick, 2001). Reaction time is one of the important variables used to study a person's central information processing speed and fast coordinated peripheral movement response. Slowed performance is usually accompanied by prolonged simple reaction time (Bruhn \& Parsons, 1971).

The aim of this study was to compare agility time in table tennis players and sedentary subjects of different ages and also to investigate the relationship between agility time and age in these groups.

\section{Methods}

\section{Participants}

The experimental group consisted of 44 male competitive table tennis players playing actively at the level of performance around $3^{\text {rd }}$ and $4^{\text {th }}$ league in Bratislava region (Slovak Republic). They had one match and from 2 to 3 training sessions for two hours per week. The control group consisted of 48 males classified as a sedentary. Definition of sedentary includes those who undertake no leisure-time activity and those undertake $<30$ minutes of physical activity each day (Booth \& Chakravarthy, 2002). Both groups were divided into four age-related categories: young (20 to 29 years), early middle-aged (30 to 44 years), late middle-aged subjects (45 to 59 years) and older subjects (60 to 70 years) (Tables 1 and 2). All of them were informed of the procedures and the main purpose of this study and gave written, informed consent. Proceedings of testing were in accordance with the ethical standards on human experimentation as stated in the Helsinki Declaration.

\section{Procedure}

The testing of table tennis players was performed in a gym at the table tennis table. The control group performed the test in a community centre under the same conditions. Prior to the study, participants attended a familiarization session during which the testing conditions were explained.

Afterwards, they performed Agility test adjusted to the needs of table tennis meaning that localization of contact mats was in accordance with sport-specific tasks. They were placed in the corners of the standard table tennis table (table width $1.525 \mathrm{~m}$ ) for reaction with dominant hand (hand which holds a racquet) to forehand or backhand side. Subjects were positioned in the middle of the table ( $50 \mathrm{~cm}$ from the table) and they had to take a step and touch one of the mats as fast as possible in accordance with the location of the visual stimulus appearing in one of two corners of the screen only with dominant hand (hand holding a racquet). After every reaction they had to move back to the starting position. As a stimulus, a yellow circle on the blue screen background was used.

The test consisted of 32 visual stimuli (16 in each direction) with random generation of their location and generation time from 200 to $500 \mathrm{~ms}$. The test result was an average agility time of the 16 best reactions ( 8 in each direction) in better of two repetitions. Data were collected using FiTRO Agility check (FiTRONIC,

Table 1

Characteristics of table tennis players (mean $\pm S D$ )

\begin{tabular}{lrccc}
\hline $\begin{array}{l}\text { Age category } \\
\text { (years) }\end{array}$ & $n$ & $\begin{array}{c}\text { Age } \\
\text { (years) }\end{array}$ & $\begin{array}{c}\text { Height } \\
(\mathrm{cm})\end{array}$ & $\begin{array}{c}\text { Body mass } \\
(\mathrm{kg})\end{array}$ \\
\hline $20-29$ & 9 & $26.2 \pm 2.9$ & $185.2 \pm 9.4$ & $79.7 \pm 12.2$ \\
$30-44$ & 17 & $39.3 \pm 4.4$ & $180.1 \pm 5.8$ & $90.6 \pm 15.8$ \\
$45-59$ & 11 & $52.1 \pm 3.6$ & $175.0 \pm 4.2$ & $91.6 \pm 18.8$ \\
$60-70$ & 7 & $62.7 \pm 2.2$ & $174.1 \pm 3.8$ & $85.6 \pm 13.4$ \\
\hline
\end{tabular}

Table 2

Characteristics of sedentary subjects (mean $\pm S D$ )

\begin{tabular}{lcccc}
\hline $\begin{array}{l}\text { Age category } \\
\text { (years) }\end{array}$ & $n$ & $\begin{array}{c}\text { Age } \\
\text { (years) }\end{array}$ & $\begin{array}{c}\text { Height } \\
(\mathrm{cm})\end{array}$ & $\begin{array}{c}\text { Body mass } \\
(\mathrm{kg})\end{array}$ \\
\hline $20-29$ & 11 & $24.1 \pm 3.1$ & $185.3 \pm 8.6$ & $88.0 \pm 12.6$ \\
$30-44$ & 12 & $34.8 \pm 4.1$ & $179.6 \pm 6.4$ & $87.5 \pm 13.8$ \\
$45-59$ & 14 & $52.1 \pm 4.8$ & $175.1 \pm 5.5$ & $88.4 \pm 13.7$ \\
$60-70$ & 11 & $65.0 \pm 2.9$ & $175.5 \pm 6.2$ & $87.9 \pm 16.1$ \\
\hline
\end{tabular}


Bratislava, Slovak Republic). The reliability of the test procedure had been verified previously, and the testing protocol had been standardized by the examination of 196 participants (Zemková \& Hamar, 1998). The analysis of repeated measurements showed a measurement error of $7.1 \%$, which is within a range comparable to common motor tests (Faber, Nijhuis-Van Der Sanden, Elferink-Gemser, \& Oosterveld, 2015).

\section{Statistical analysis}

The collected data was processed statistically using Statistica (Version 12.0; TIBCO Software, Palo Alto, CA, USA). The Kolmogorov-Smirnov test for normality and Levene's test for homogeneity of variances were performed on all variables, which revealed that data was normally distributed and detected no significant differences in sample variances. The one-way analysis of covariance (ANCOVA) was conducted to determine a significant difference between table tennis players and sedentary subjects in agility time after controlling the age. The $t$-test for two independent samples was used to determine significant differences in BMI, height and body mass between these groups. To determine significant differences between each age category of players and sedentary subjects, Mann-Whitney $U$-test was performed. To determine effect size, Cohen's $r$ (the value of $.1 \leq r<.3$ - small effect, $.3 \leq r<.5-$ medium effect, $.5 \leq r-$ high effect) was used. Parametric Pearson's correlation coefficient $\left(r_{\mathrm{p}}\right)$ was applied to evaluate the association of agility time and age in all table tennis players and in all sedentary subjects. The level of significance was set at $\alpha=.05$.

\section{Results}

The participant's age, height and body mass are described in Tables 1 and 2. There were no significant differences between players and sedentary subjects in BMI $(t=0.12, p=.46)$, height $(t=0.19, p=.42)$ and body mass $(t=0.12, p=.45)$. Therefore, these parameters were not included in any further analysis.
The one-way ANCOVA indicated a significant difference in agility time between two groups when the effect of age was controlled $(F(1,89)=46.1, p<.001)$.

Agility time was significantly lower in table tennis players compared to sedentary subjects of early middleaged $(435.8 \pm 35.6 \mathrm{~ms}$ and $483.8 \pm 36.5 \mathrm{~ms}$, respectively; $p=.006)$, late middle-aged $(481.0 \pm 36.8 \mathrm{~ms}$ and $530.7 \pm 31.8 \mathrm{~ms}$, respectively; $p=.004)$ and older subjects $(500.9 \pm 24.4 \mathrm{~ms}$ and $564.5 \pm 44.9 \mathrm{~ms}$, respectively; $p=.007)$. However, the values did not differ significantly between young players and young sedentary subjects (Table 3).

Agility time in table tennis players was significantly lower in early middle-aged than in late middle-aged subjects $(435.8 \pm 35.6 \mathrm{~ms}$ and $481.0 \pm 36.8 \mathrm{~ms}$, respectively; $p=.007)$. There were no significant differences in agility time between young and early middle-aged and between late middle-aged and older table tennis players (Table 4).

Agility time in sedentary subjects was significantly lower in early middle-aged than in late middle-aged subjects $(483.8 \pm 36.5 \mathrm{~ms}$ and $530.7 \pm 31.8 \mathrm{~ms}$, respectively; $p=.042$ ). There was no significant difference in agility time between young and early middle-aged and between late middle-aged and older sedentary subjects (Table 5).

Furthermore, there was a significant relationship between agility time and age in both table tennis players $\left(r_{\mathrm{p}}=.53, p<.001\right)$ and sedentary subjects $\left(r_{\mathrm{p}}=.73\right.$, $p<.001)$ as shown in Figure 1.

\section{Discussion}

The study showed that table tennis players have better agility performance compared to sedentary subjects. In three of four age categories of players was showed shorter agility time than sedentary subjects. The biggest difference was found between older subjects (11.3\%) followed by early middle-aged $(9.9 \%)$ and late middleaged subjects $(9.4 \%)$. This may be ascribed that playing table tennis is beneficial to eye-hand reaction time and

Table 3

Agility time (mean $\pm S D$ ) in table tennis players and sedentary subjects of different ages

\begin{tabular}{|c|c|c|c|c|}
\hline \multirow{2}{*}{$\begin{array}{l}\text { Age category } \\
\text { (years) }\end{array}$} & \multicolumn{2}{|c|}{ Agility time (ms) } & \multirow[b]{2}{*}{$p$} & \multirow[b]{2}{*}{ Cohen's $r$} \\
\hline & Table tennis players & Sedentary subjects & & \\
\hline $20-29$ & $433.0 \pm 28.1$ & $461.3 \pm 30.0$ & .069 & .41 \\
\hline $30-44$ & $435.8 \pm 35.6$ & $483.8 \pm 36.5$ & .006 & .51 \\
\hline $45-59$ & $481.0 \pm 36.8$ & $530.7 \pm 31.8$ & .004 & .57 \\
\hline $60-70$ & $500.9 \pm 24.4$ & $564.5 \pm 44.9$ & .007 & .64 \\
\hline
\end{tabular}


Table 4

Agility time (mean $\pm S D$ ) and interdifference matrix between agility times of table tennis players of different ages

\begin{tabular}{lcccc}
\hline \multirow{2}{*}{$\begin{array}{l}\text { Age category } \\
\text { (years) }\end{array}$} & $\begin{array}{c}\text { Agility time } \\
(\mathrm{ms})\end{array}$ & \multicolumn{3}{c}{$p$} \\
\cline { 3 - 5 } & $433.0 \pm 28.1$ & - & & \\
\hline $20-29$ & $435.8 \pm 35.6$ & .700 & - & \\
$30-44$ & $481.0 \pm 36.8$ & .012 & .007 & - \\
$45-59$ & $500.9 \pm 24.4$ & .003 & $<.001$ & .317 \\
$60-70$ & & & & \\
\hline
\end{tabular}

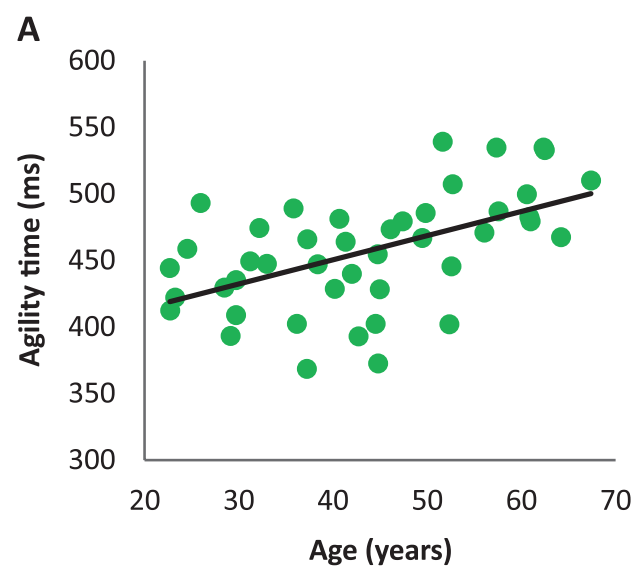

Table 5

Agility time (mean $\pm S D$ ) and interdifference matrix between agility times of sedentary subjects of different ages

\begin{tabular}{lcccc}
\hline \multirow{2}{*}{$\begin{array}{l}\text { Age category } \\
\text { (years) }\end{array}$} & $\begin{array}{c}\text { Agility time } \\
(\mathrm{ms})\end{array}$ & \multicolumn{4}{c}{$p$} \\
\cline { 3 - 5 } $20-29$ & $461.3 \pm 30.0$ & - & & \\
$30-44$ & $483.8 \pm 36.5$ & .168 & - & \\
$45-59$ & $530.7 \pm 31.8$ & $<.001$ & .005 & - \\
$60-70$ & $564.5 \pm 44.9$ & $<.001$ & $<.001$ & .085 \\
\hline
\end{tabular}

B

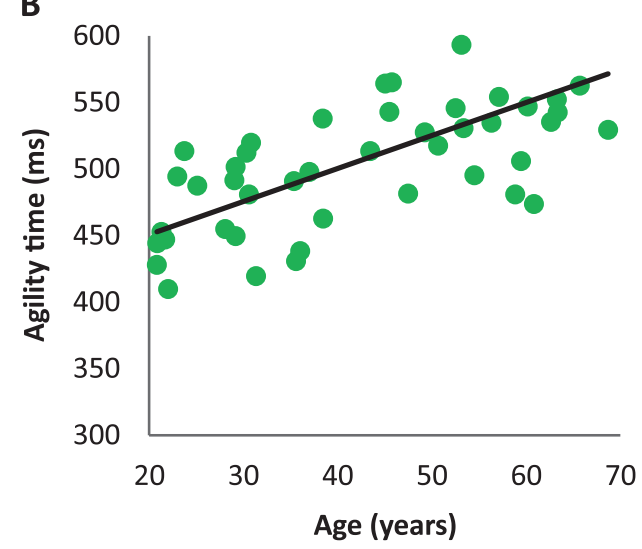

Figure 1. Relationship between agility time and age in table tennis players (A) and sedentary subjects (B).

for this reason players have faster reaction time than healthy controls (Bhabhor et al., 2013). In particular, table tennis players have significantly shorter visual reaction time than control group (Can et al., 2014; Padulo et al., 2016).

In the present study, the smallest difference between players and sedentary was found in the young subjects. The players were better only by $28.3 \mathrm{~ms}$ (6.1\%). This may be due to the fact, that the first decade of adulthood is considered as a peak of motor performance, health and strength (Gregor, 2014). The best agility performance is achieved about the age of 20 (Zemková \& Hamar, 2001). It seems that playing table tennis is not as beneficial from the point of agility time as it is in middle-aged and older subjects. On the other side, the study of Gavkare, Nanaware, and Surdi (2013) showed, that the whole body reaction time (reaction time and movement of lower limbs) is significantly lower in young athletes compared to healthy control group.

Agility time as well as reaction time increases with increasing age. In childhood, it decreases with increasing age up to early maturity (Zemková \& Hamar, 2001). However, there are no studies investigating the changes in agility time throughout adulthood. This study showed that agility time increased from young to older age by $18.3 \%$ in sedentary subjects. However, in table tennis players the increase was only $14.1 \%$. The steepest increase of agility time was found between early middle-aged and late middle-aged players and sedentary subjects, too ( $9.4 \%$ and $8.8 \%$, respectively). This may be attributed to the fact that the majority of age-related differences in cognition were detected in the transition from middle-aged (50 years) to old age (65 years), several age-related differences such as cognitive reaction time, executive control, complex visuoconstructive and visuospatial functions were evident before age of 50 (Ferreira et al., 2015). Increase in agility time between late middle-aged and older sedentary subjects was by $6 \%$, whereas in table tennis players it was only by $4 \%$. The same difference in increase of agility time was between young and early middle-aged subjects $(0.7 \%$ in players and $4.7 \%$ in sedentary subjects, respectively). There was clear evidence that agility time increased throughout the adulthood similarly to choice reaction time (Der \& Deary, 2006). Moreover, older subjects (60 years and older) responded more slowly 
than two younger groups (aged $<50$ and $50-59$ years) in dual-task condition, but not in simple-task reaction times (Makizako, Kaneko, Aoki, \& Ihira, 2013).

There was a significant relationship between agility time and age in table tennis players $\left(r_{\mathrm{p}}=.53\right)$ and sedentary subjects $\left(r_{\mathrm{p}}=.73\right)$. Similar relationship between choice reaction time and age $\left(r_{\mathrm{p}}=.47\right)$ was reported by Woods et al. (2015). On the other hand, correlation analyses failed to find a significant relationship between age and simple/procedural reaction time in younger (age 21-38) and older (age 39-58) military personnel (Alfred \& Rice, 2012). Furthermore, a significant positive correlation was found between age and reaction times in a dual-task condition $\left(r_{\mathrm{p}}=.45\right)$, but not in simple-task condition $\left(r_{\mathrm{p}}=.21\right)$ (Makizako et al., 2013).

Table tennis can be one of alternatives to keep a good level of agility performance at any age especially in late middle-aged subjects when it tends to decrease more markedly.

There are some limitations of this study. We did not observe any factors influencing perceptual component of agility performance and speed of decision-making, for example fatigue, alcohol or caffeine (Sabzi, 2012; Santos et al., 2014; Tzambazis \& Stough, 2000). Furthermore, we did not take into account a duration (or years of practise) of playing table tennis. Playing table tennis for longer duration has shorter visual reaction time compared to short duration of playing (Vidja et al., 2012). Therefore, we were not able to investigate which of the components of the agility performance (perceptual, decision-making or motor performance) is deteriorating steeper with increasing age. This might be the objective of another study with usage of an enhanced device.

\section{Conclusions}

Agility time correlates significantly with age in both table tennis players and sedentary subjects. These values are significantly lower in early middle-aged, late middle-aged and older ( $\geq 60$ years) table tennis players than in sedentary subjects. These findings indicate that playing table tennis contributes to better agility time in middle-aged and older subjects as compared to those with a predominantly sedentary lifestyle.

\section{Conflict of interest}

There were no conflicts of interest.

\section{References}

Ak, E., \& Kocak, S. (2010). Coincidence-anticipation timing and reaction time in youth tennis and table tennis players. Perceptual and Motor Skills, 110, 879-887.

Alfred, P. E., \& Rice, V. J. (2012). Age differences in simple and procedural reaction time among healthy military personnel. Proceedings of the Human Factors and Ergonomics Society Annual Meeting, 56, 1809-1813.

Bhabhor, M. K., Vidja, K., Bhanderi, P., Dodhia, S., Kathrotia, R., \& Joshi, V. (2013). A comparative study of visual reaction time in table tennis players and healthy controls. Indian Journal of Physiology and Pharmacology, 57, 439-442.

Booth, F. W., \& Chakravarthy, M. V. (2002). Cost and consequences of sedentary living: New battleground for an old enemy. President's Council on Physical Fitness and Sport Research Digest, 3, 3-8.

Bruhn, P., \& Parsons, O. P. (1971). Continuous reaction time in brain damage. Cortex, 7, 278-291.

Can, S., Kilit, B., Arslan, E., \& Suveren, S. (2014). The comparison of reaction time of male tennis players, table tennis players and the ones who don't exercise at all in 10 to 12 age group. Nigde University Journal of Physical Education and Sport Sciences, 8, 195-201.

Chandak, P. R., \& Makwana, J. (2012). Ageing \& reaction time in Indian population. People's Journal of Scientific Research, 5, 36-39.

Der, G., \& Deary, I. J. (2006). Age and sex differences in reaction time in adulthood: Results from the United Kingdom Health and Lifestyle Survey. Journal of Psychology and Ageing, 21, 62-73.

Dube, S. P., Mungal, S. U., \& Kulkarni, M. B. (2014). Simple visual reaction time in badminton players: A comparative study. National Journal of Physiology, Pharmacy \& Pharmacology, 5, 18-20.

Faber, I. R., Nijhuis-Van Der Sanden, M. W., Elferink-Gemser, M. T., \& Oosterveld, F. G. (2015). The Dutch motor skills assessment as tool for talent development in table tennis: A reproducibility and validity study. Journal of Sports Sciences, 33, 1149-1158.

Ferreira, D., Correia, R., Nieto, A., Machado, A., Molina, Y., \& Barroso, J. (2015). Cognitive decline before the age of 50 can be detected with sensitive cognitive measures. Psicothema, 27, 216-222.

Foroghipour, H., Monfared, M. O., Pirmohammadi, M., \& Saboonchi, R. (2013). Comparison of simple and choice reaction time in tennis and volleyball players. International Journal of Sport Studies, 3, 74-79.

Gavkare, A. M., Nanaware, L. N., \& Surdi, A. D. (2013). Auditory reaction time, visual reaction time and whole body reaction time in athletes. Indian Medical Gazette, 147, 214-219.

Gregor, T. (2014). Základy všeobecnej a vývinovej psychológie [The foundations of general and developmental psychology]. Bratislava, Slovak Republic: Mauro Slovakia.

Harada, C. N., Natelson Love, M. C., \& Triebel, K. L. (2013). Normal cognitive aging. Clinics in Geriatric Medicine, 29, 737-752.

Jakobsen, L. H., Sorensen, J., Rask, I. K., Jensen, B. S., \& Kondrup, J. (2011). Validation of reaction time as a 
measure of cognitive function and quality of life in healthy subjects and patients. Applied Nutritional Investigation, 27, 561-570.

Lord, S. R., \& Fitzpatrick, R. C. (2001). Choice stepping reaction time: A composite measure of falls risk in older people. Journals of Gerontology, Series A, 56, 627-632.

Luchies, C. W., Schiffman, J., Richards, L. G., Thompson, M. R., Bazuin, D., \& Deyoung, A. J. (2002). Effect of age, step direction and reaction condition on the ability to step quickly. Journals of Gerontology, Series A, 57, 246-249.

Makizako, H., Kaneko, F., Aoki, N., \& Ihira, H. (2013). Agerelated differences in reaction time responses under simple- and dual-task conditions in middle-aged ski marathon amateur males. International Journal of Sport and Health Science, 11, 33-38.

Padulo, J., Pizzolato, F., Tosi Rodrigues, S., Migliaccio, G. M., Attene, G., Curcio, R., \& Zagatto, A. M. (2016). Task complexity reveals expertise of table tennis players. Journal of Sport Medicine and Physical Fitness, 56, 149-156.

Sabzi, A. H. (2012). The effect of different fatigue protocols on choice reaction time. Middle-East Journal of Scientific Research, 12, 1092-1096.

Santos, V. G. F., Santos, V. R. F., Felippe, L. J. C., Almeida, J. W., Jr., Bertuzzi, R., Kiss, M. A. P. D. M., \& Lima-Silva, A. E. (2014). Caffeine reduces reaction time and improves performance in simulated-contest of taekwondo. Nutrients, 6, 637-649.

Seidler, R. D., Bernard, J. A., Burutolu, T. B., Fling, B. W., Gordon, M. T., Gwin, J. T., ... Lipps, D. B. (2010). Motor control and aging: Links to age-related brain structural, functional, and biomechanical effects. Neuroscience \& Biobehavioral Reviews, 34, 721-733.

Tzambazis, K., \& Stough, C. (2000). Alcohol impairs speed of information processing and simple and choice reaction time and differentially impairs higher-order cognitive abilities. Alcohol and Alcoholism, 35, 197-201.

Vacenovský, P., \& Vencúrik, T. (2013). Improvement of reaction time through the one semester course of table tennis for non-athlete students. In M. Zvonař \& Z. Sajdlová (Eds.), Proceedings of the $9^{\text {th }}$ International Conference Sport and Quality of Life 2013 (pp. 200-206). Brno, Czech Republic: Masaryk University.

Vidja, K., Shital, D., Mahesh, B., Proti, B., Jatin, C., \& Hitesh, J. (2012). Long term playing of table tennis improve the visual reaction time. International Journal of Scientific Research, 1, 155-156.

Vidja, K. R., Bhabhor, M. K., Sarvaniya, J. L., Patel, N. S., \& Joshi, V. (2015). Long term playing of badminton improves the visual reaction time. International Journal of Research in Medicine, 4, 90-92.

Woods, D. L., Wyma, J. M., Yund, E. W., Herron, T. J., \& Reed, B. (2015). Age-related slowing of response selection and production in a visual choice reaction time tasks. Frontiers in Human Neuroscience, 9, 193.

Yoshida, K., Hiruta, S., Shimaoka, M. K., Ilmoto, Y., Furukawa, K., Takeuchi, T., \& Yuza, N. (1995). A study on spin control techniques for chop and float services in table tennis. In Y. Hatano (Ed.), Proceedings in FISU/CESU Conference: The $18^{\text {th }}$ Universiade 1995 Sports and Man (pp. 364-365). Fukuoka, Japan: Organizing Committee for the Universiade 1995.

Zemková, E., \& Hamar, D. (1998). Test disjunktívnych reakčno-rýchlostných schopností dolných končatín [Test of disjunctive reaction-speed abilities of lower limbs]. In M. Janura (Ed.), Sborník referátů z celostátní studentské védecké konference v oboru kinantropologie (pp. 178-181). Olomouc, Czech Republic: Palacký University Olomouc.

Zemková, E., \& Hamar, D. (2001). Posudzovanie disjunktívnych reakčno-rýchlostných schopností [Assessment of disjunctive reaction-speed abilities]. Bratislava, Slovak Republic: Comenius University in Bratislava in cooperation with Slovak Science Company.

Zemková, E., \& Hamar, D. (2015). Toward an understanding of agility performance (2nd ed.). Bratislava, Slovak Republic: Comenius University in Bratislava. 